Special Issue of the 8th International Advances in Applied Physics and Materials Science Congress (APMAS 2018)

\title{
Manufacturing of Magnetic Zinc Oxide Particles Synthesized by Sol-Gel for Radar Absorbing Applications
}

\author{
H. YilmaZ ATAY* AND Ö. İÇIN \\ İzmir Katip Çelebi University, Department of Material Science and Engineering, İzmir Turkey
}

\begin{abstract}
The fundamental operation of radar is transmission and reception of electromagnetic waves. When the waves strike an object, some portion is reflected, some transmitted and some absorbed by the object. If the received or absorbed parts are bigger then reflected, the object may not be dedected by the radar. In this study, it was aimed to produce radar absorbing materials with this principle especially for certain military applications focused on defence and security. Magnetic zinc oxide particles were synthesized by sol-gel. They were embedded to a polymeric matrix with different loading level to see the concentration dependence. The particles were characterized by X-Ray diffraction. Under applied magnetic field, the produced composites exhibited the hysteresis loops of the ferromagnetic behavior with vibrating sample magnetometer. In addition, radar absorbing test was applied as a primary objective of this research with a network analyzer. It was concluded that Fe doped zinc oxide composites have electromagnetic properties which indicate potential application in radar absorbing applications.
\end{abstract}

DOI: 10.12693/APhysPolA.135.908

PACS/topics: radar absorbing materials, magnetic properties, zinc oxide, sol-gel, Fe-doped

\section{Introduction}

When radar waves hit an object, some of this returned to the radar set, where it is detected. The amount of reflection depends on both surface properties and the properties of the matter which the wave was originally traveling through [1]. Radar absorbing materials are designed to this simple principle; reducing the returned signal. They can be produced by altering dielectric and magnetic properties of existing materials. According to purposes of analysis, the dielectric properties of a material are classed as its permittivity and the magnetic properties as its permeability. Foams, plastics, and elastomers that are known as common dielectric materials are used for absorbers, have no magnetic properties. Ferrites, iron, and cobalt nickel alloys which are magnetic materials, are used to change the permeability of the base materials $[2,3]$. In this study, Fe-doped zinc oxide was used as magnetic material. Zinc oxide is II-VI type binary semiconductor compound with a wide band gap $(3.37 \mathrm{eV})$ at room temperature. Thermodynamically, hexagonal wurtzite phase of $\mathrm{ZnO}$ is stable at room temperature, in which each cation $\left(\mathrm{Zn}^{2+}\right)$ is surrounded by four anions $\left(\mathrm{O}^{2-}\right)$ at the corners of a tetrahedron [4]. Incorporation of the transition metal ions into the material is one way of altering properties of $\mathrm{ZnO}$. This may change the magnetism and conducting properties of the $\mathrm{ZnO}$. For this purpose, Fe-doped zinc oxide particles were synthesized via Sol-Gel method with doping concentrations of $0 \%$, $3 \%, 6 \%$ and $9 \%$. Prepared powders were characterized by using X-ray diffraction (XRD). Magnetic characterization was carried out using vibrating sample magne-

*corresponding author; e-mail: hgulyilmaz@gmail.com tometer (VSM). Radar absorbing test was applied with a Network Analyzer to achieve the main purpose of this research.

\section{Experimental procedure}

The used precursors are zinc acetate dihydrate $\left(\mathrm{C}_{4} \mathrm{H}_{6} \mathrm{O}_{4} \mathrm{Zn} \cdot 2 \mathrm{H}_{2} \mathrm{O}\right.$, Aldrich) and iron(IV) nitrate nonahydrate $\left(\mathrm{FeN}_{3} \mathrm{O}_{9} \cdot 9 \mathrm{H}_{2} \mathrm{O}\right.$, Aldrich), as a complexing agent is citric acid monohydrate $\left(\mathrm{C}_{6} \mathrm{H}_{8} \mathrm{O}_{7} \cdot \mathrm{H}_{2} \mathrm{O}\right.$, Aldrich) for the synthesizing of Fe-doped Zinc oxide powders by Sol-Gel. The following compositions of $\mathrm{Zn}_{1-x} \mathrm{Fe}_{x} \mathrm{O}$, with $x=0$, 0.03, 0.06 and $0.09 \mathrm{~mol}$, were prepared. Zinc acetate and iron nitrate were separately dissolved in distilled water. The solution were mixed by magnetic stirrer until the transparent solution was obtained. The solution was kept at $80^{\circ} \mathrm{C}$ in air until wet gel with high viscosity was obtained. The wet gel was treated at $130^{\circ} \mathrm{C}$ for $12 \mathrm{~h}$ in oven to prepare dry gel. The dry gel was exposed to sintering process at $500{ }^{\circ} \mathrm{C}$ for $3 \mathrm{~h}$ to evaporate impurities and in air in a ash furnace. The phase analysis of the powders was performed with the help of a Empyrean X-ray diffractometer with $\mathrm{Cu} K \alpha$ radiation $(\lambda=1.540 \AA)$, in the $2 \theta$ range of $20-80^{\circ}$. The room temperature magnetic behavior was evaluated by using VSM 550-100 vibrating sample magnetometer and polytetrafluoroethylene teflon tape (PTFE). For radar absorbing determination, obtained Fe-doped $\mathrm{ZnO}$ powders were embedded to styrofoam sheet blocks. Absorbing properties were measured with transmission/reflection method in the region of 8-12 GHz. with a Network Analyzer HP8720D and coaxial line fixture.

\section{Results and discussion}

Figure 1 shows XRD patterns of Fe-doped $\mathrm{ZnO}$ powders $\left(\mathrm{Zn}_{1-x} \mathrm{Fe}_{x} \mathrm{O}\right.$, with $x=0,0.03,0.06$ and $\left.0.09 \mathrm{~mol}\right)$. It revealed that all peaks correspond to (100), (002), 


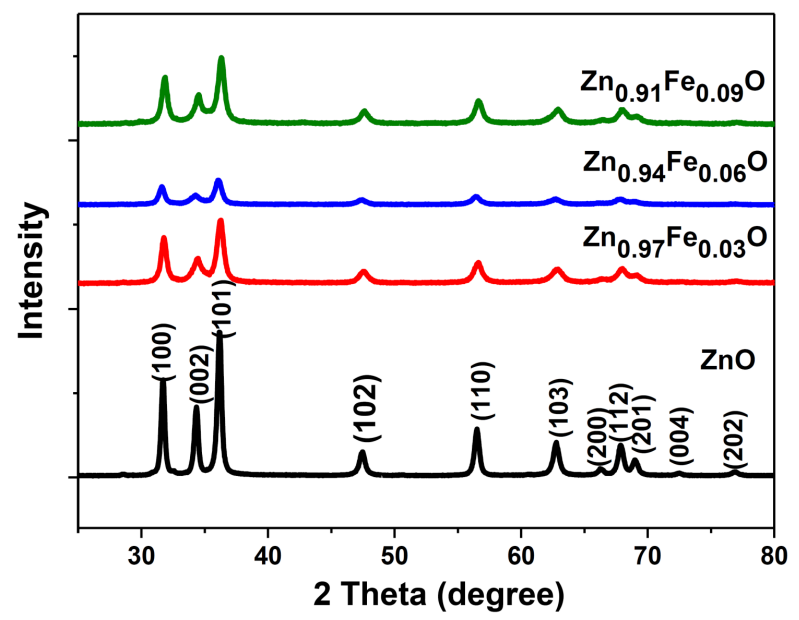

Fig. 1. XRD patterns of $\mathrm{Fe}$ doped $\mathrm{ZnO}$ powders produced by sol-gel method.
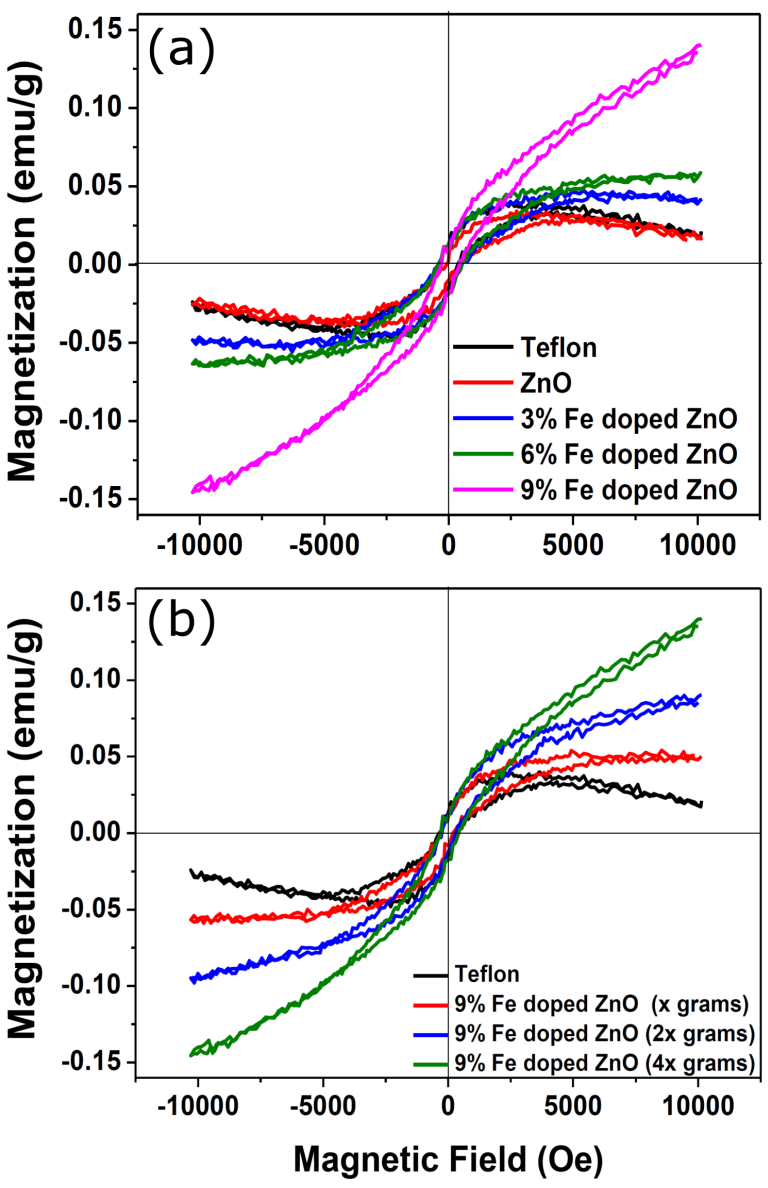

Fig. 2. M-H curves of: (a) $\mathrm{Zn}_{1-x} \mathrm{Fe}_{x} \mathrm{O}$, (b) different weight of $\mathrm{Zn}_{0.91} \mathrm{Fe}_{0.09} \mathrm{O}$.

(101), (102), (103), (110) and (112) planes related to the hexagonal wurtzite crystal structure. The wurtzite structure $\mathrm{ZnO}$ with Fe doped concentration up to $9 \%$, in agreement with JCPDS card no: 89-0510 [4, 5]. There is no sign related iron metal, oxides, or any binary zinc iron phases. All the powders showed peaks similar to pure $\mathrm{ZnO}$, which indicates that no structural deformation occurred in $\mathrm{ZnO}$ lattice upon Fe-doping. This supports successful substitutional replacement of Fe ions in $\mathrm{Zn}$ lattice sites in the $\mathrm{ZnO}$ matrix. But, a change in the preferred orientation from (002) to (101) plane was noticed with the increasing doping concentration that might be due to the presence of Fe content.

The magnetic hysteresis (M-H) curves of the powders are shown in Fig. 2a and b. Fe doped $\mathrm{ZnO}$ powders show high saturation magnetization compared to un-doped $\mathrm{ZnO}$. As it is known that pure $\mathrm{ZnO}$ has paramagnetic behavior, the observed ferromagnetism in $\mathrm{Zn}_{1-x} \mathrm{Fe}_{x} \mathrm{O}$ was originated from the Fe substitution for $\mathrm{Zn}$ in $\mathrm{ZnO}$ [6]. Another possible explanation is related to a nanoscale phase separation responsible for the presence of Fe-rich magnetic nanoparticles [7]. These particles can take form of a-Fe, various Fe-oxides and/or condensed ( $\mathrm{Zn}$, $\mathrm{Fe}$ ) $\mathrm{O}$, from the XRD results, $\mathrm{Fe}^{3+}$ and $\mathrm{Fe}^{2+}$ ions coexsist in the powders by substituting on the $\mathrm{Zn} 2+$ site. Figure 2a shows that with increasing Fe content from 0 to 0.09 , saturation magnetization was increased from 0.035 to $0.14 \mathrm{emu} / \mathrm{g}$. Effect of the amount of Fe-doped $\mathrm{ZnO}$ is shown in Fig. 2b. The highest Fe content $\mathrm{ZnO}$ $\left(\mathrm{Zn}_{0.91} \mathrm{Fe}_{0.09} \mathrm{O}\right)$ were used at different weight ratio to compare the amount effect. With increasing weight ratio of $9 \%$ Fe doped $\mathrm{ZnO}$, saturation magnetization increased from 0.05 to 0.14 .
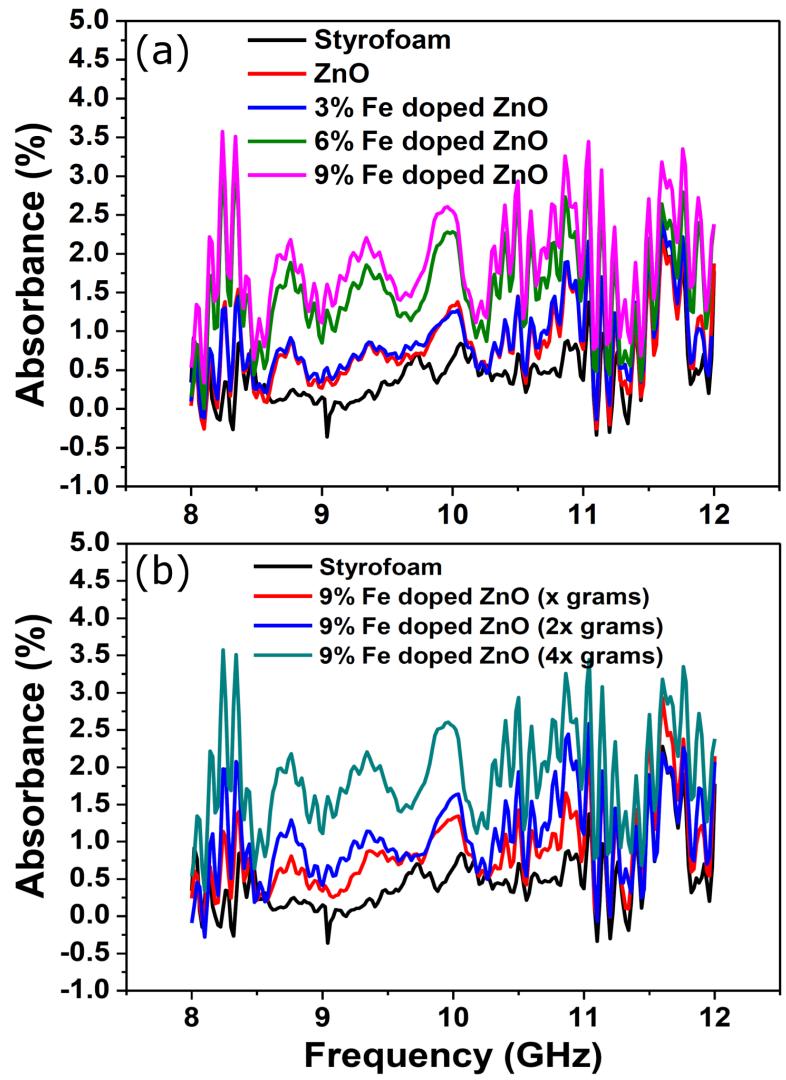

Fig. 3. Absorbance of: (a) $\mathrm{Zn}_{1-x} \mathrm{Fe}_{x} \mathrm{O}$, (b) different weight of $\mathrm{Zn}_{0.91} \mathrm{Fe}_{0.09} \mathrm{O}$. 
Figure 3a depicts microwave absorption characteristics of the pure styrofoam sheets block and Fe-doped $\mathrm{ZnO}$ $(3,6$ and $9 \%)$ reinforced styrofoam sheets blocks. It is clear to see that there was no any radar absorbing activity in pure styrofoam. While, Fe doped $\mathrm{ZnO}$ powders reinforced ones show a significant absorbing activities. The radar wave absorbing property was substantially improved after the addition of $\mathrm{Fe}$ doped $\mathrm{ZnO}$; absorbing percentage increases with increasing Fe content [3]. The highest absorbing peak reaches $3.5 \%$ at $8.36 \mathrm{GHz}$ with the $9 \% \mathrm{Fe}$ doped $\mathrm{ZnO}$. In Fig. 3b, the highest Fe content $\mathrm{ZnO}$ powders $\left(\mathrm{Zn}_{0.91} \mathrm{Fe}_{0.09} \mathrm{O}\right)$ were used at different amount in composite. The higher absorption values were reached with highest quantity of $9 \%$ Fe doped $\mathrm{ZnO}$ powders. There are two possible outcomes from the findings; increasing $\mathrm{Fe}$ content in $\mathrm{ZnO}$ powders increasing radar absorbing property, and increasing additive content level improved radar absorbing behaviour.

\section{Conclusion}

Fe-doped $\mathrm{ZnO}$ powders with the atomic fraction, $x$, in the range of $0-0.9$ were successfully prepared by using simple and economic sol-gel process. Effect of doping concentration on the structural and magnetic properties of Fe-doped $\mathrm{ZnO}$ powders was studied. XRD results confirmed the presence of hexagonal wurtzite structure for all the synthesized samples and there are not any secondary phases and $\mathrm{Fe}^{2+}$ as well as $\mathrm{Fe}^{3+}$ substituted for $\mathrm{Zn}^{2+}$ of $\mathrm{ZnO}$ host. VSM results showed that room temperature ferromagnetic property enhanced with increase in doping concentration of iron. The observed ferromagnetism in the samples originates from the Fe substitution for $\mathrm{Zn}$ in $\mathrm{ZnO}$, which follows the electron doubleexchange mechanism. The maximum saturation magnetization $(0.14 \mathrm{emu} / \mathrm{g})$ for sample with $9 \%$ doping concentration was obtained. It was not seen any absorbing activity in $0 \%$ additive content composite. However, in the highest loading level of $9 \%$ Fe-doped $\mathrm{ZnO}$ powders reinforced styrofoam sheets, there were significant absorbing activity. Absorption values were increased by increasing content of $\mathrm{Fe}$ in the $\mathrm{ZnO}$ powders, and also by increasing additive content between styrofoam sheets.

\section{References}

[1] F. Qin, C. Brosseau, J. Appl. Phys. 111, 061301 (2012).

[2] H. Kojima, in: Ferromagnetic Materials: A Handbook on the Properties of Magnetically Ordered Substances, Ed. E.P. Wohlfarth, 3rd ed., ch. 5, North Holland, Amsterdam 1982.

[3] H. Yılmaz Atay, E. Çelik, Polym. Comp. 35, 602 (2014).

[4] T. Srinivasulu, K. Saritha, K.T. Reddy, Mod. Electr. Mater. 3, 76 (2017).

[5] T.M. Hammad, S. Griesing, M. Wotocek, S. Kuhn, R. Hempelmann, U. Hartmann, J.K. Salem, Int. J. Nanopart. 6, 324 (2013).

[6] A. Baranowska-Korczyc, A. Reszka, K. Sobczak, B. Sikora, P. Dziawa, M. Aleszkiewicz, Ł. Kłopotowski, W. Paszkowicz, P. Dłużewski, B.J. Kowalski, T.A. Kowalewski, M. Sawicki, D. Elbaum, K. Fronc, J Sol-Gel Sci. Technol. 61, 494 (2012).

[7] A. Bonanni, T. Dietl, Chem. Soc. Rev. 39, 528 (2010). 